\title{
The Response of Confucianism to the Spiritual Crisis of Modernity--And its Comparison with Western Philosophy
}

\author{
Bing Yang \\ Southwest Minzu University, Chengdu, 610041, China
}

Keywords: Modernity; spiritual crisis; individualism; Confucianism.

\begin{abstract}
Modernity mainly refers the characteristics of the times shaped by the modernization process from the traditional agricultural society to the modern industrial society. Also, modernity can be defined as modern capitalism constructed by the market economy, the individualistic spirit, the highly developed instrumental rationality and other factors. Modernity brings advanced technology, institutions and concepts to society, and makes mankind move towards a higher civilization, while it also brings a lot of negative things, one of which is spiritual crisis. That is to say, modernity has brought mankind out of the external "cage" and into the inner "prison". This is one of the contradictions that human beings can never avoid; Western scholars have done active treatment from different levels, and Confucianism also responds accordingly based on its deep historical accumulation and cultural and social training. Confucianism or Confucian thoughts have contributed traditional order factors and positive adaptive ability in the process of modernization in China, and have gained new moral functions in the new environment of modernization. Confucianism and its built lifestyle still maintain the vitality inherent in China and has so far exerted its influence. So, whether Confucianism or Confucian thoughts can deal with the core issue of the modernity crisis---the loss of life or the meaning of life will be a question that is extremely practical and needs to be answered. This paper attempts to demonstrate the tolerance of Confucianism by examining the modernity and its crisis and comparing it with Western philosophy to examine the possible attitudes of Confucianism based on its ideological and lifestyle resources, to highlight the tolerance of Confucianism and the wise and great gesture of its self-contained integration into modernity.
\end{abstract}

\section{Introduction}

Kant once said: "Enlightenment is the state of human beings from the immaturity that one has added to himself. Immaturity is the powerlessness to use one's own reason without the guidance of others." Kant's definition to enlightenment highlights human rationality and subjectivity. From a sociological point of view, modernity is a common feature that is universally described in countries with advanced political, economic, technological and social development. Modernization refers to the process of acquiring these characteristics. Therefore, the sociologist Giddens said: "In a nutshell, modernity is equivalent to modernization."

Since the 18th century, with the spread of modernization in different degrees around the world, it has also brought about the advancement of science and technology, the innovation of human ideas and the liberation of individuals, and so on. Overall, human beings are moving towards a more civilized and more advanced life dimension than the pre-industrial society. But on the other hand, modernity has also spawned countless crises, including the spiritual crisis of modern people. Bennett once said: "The silence of them (medieval people) allows us to be safe and self-respecting. With their time as a reference, our time is very good. After all, who wants to live without electricity, tap water or computer? And the people of the Middle Ages would also have said: "Who is willing to live in a super-urban era threatened by the greenhouse effect and nuclear weapons?" This sentence also corresponds to Giddens's book Consequences of Modernity. Giddens believes: "The extreme expansion of the abstract system related to modernity has changed the nature of friendship." Indeed, the modernity crisis brought about by modernization has dealt a heavy blow to human beings on a 
spiritual level. The relationship between people has changed. The increase in distrust has come from the lack of security. Human beings suddenly feel lost, doubt the meaning of life, as well as the simplification of values, the supremacy of materialism, extreme expansion of individualism, etc. These are the consequences of modernity.

\section{The root cause of mental crisis}

Western scholars have noticed that the roots of people's spiritual crisis come from two aspects: First, in a society with religious traditions, modern life makes people feel that the meaning of life is worthless. This root is the lack in faith, that is, the rationality beyond the belief in the process of modernization. However, as modern rationality occupies the highlands, people begin to get rid of "God", which is followed by a break in the relationship between the shore and the other side. When the shore cannot solve the secular problem, people become at a loss and feel negative. "The rootless meaning of the individual is not the separation of the individual from others, but the separation of the moral source necessary to practice a satisfactory existence." In a society with religious beliefs, the source of morality comes from devout faith. The next is egocentrism. The individualism and democratic system brought about by modernity lead individuals to publicize their rights, value their own interests, put material interests first, and economics research is to maximize personal economic interests, which have negative effects; egocentrism leads to Individuals only pay attention to their own interests and ignore groups or others. They no longer care too much about things outside of themselves. Closed life and mediocrity without moral content can lead to meaningless life. According to the anti-rationalist position of Schopenhauer, pain and boring are the two basic elements of life, because once people reduce their desires because of satisfaction, boring emptiness will follow. It makes sense only if people must connect with others and society. Giving care to others can give them a sense of spiritual satisfaction, while purely individualism-centered ideas can lead people to fail to achieve higher goals beyond their own experience. The Russian-French philosopher Alexander Koyev once stated, "Modernity has castrated the world, made it feminine, and took away all its charm." Taylor described this as "the loss of the heroic latitude of life". "People no longer have a higher sense of purpose, and no longer feel that there is something worthy of death." It is also the negative factors of individualism that led to the loss of cultural significance and the emergence of a spiritual crisis.

\section{The spiritual crisis and meaning of saving humanity}

How should people save the human spiritual crisis brought by modernity and the loss of meaning in life? Western scholars have given two options: first, religious restoration. That is to say, in the modern life of the West, the meaning of life rooted in religion is lost with the decline of religion. To seek a meaningful life, people must return to religion. Bell once said: "If the secular system of meaning has been proved to be illusory, what should people rely on to grasp the reality? I am here to put forward a risky answer that Western society will return to a certain religious concept. It is clear that Bell means the lack of meaning in life brought about by modernity, which needs to be repaired by religion, that is, to return to religion. But Bell's meaning here is not to return to the religious life in the traditional sense, because the religious concepts after being rationally "disenchanted" can no longer bring salvation with the form only. The real redemption should be the return of the human heart, and the return to the source of religion -- the inner devout faith. Second, from the perspective of psychiatric treatment, discover the meaning of life. The representative scholars are Freud and Frankel, all of whom are from Austria, the birthplace of psychoanalysis, which we call the Austrian school. In the process of treating mental patients, they found that the senseless sense of life of modernity is eroding people's spirit. People are full of confusion and contradictions in life because of the pressure. Therefore, we must set meaningful goals for life. With these clear goals, even if we experience pain, we can still have a extremely high spiritual realm because of these goals. The above two points are the rescue schemes given by Western scholars. 


\section{The root cause of spiritual crisis in Chinese society}

The root cause of the spiritual crisis in Chinese society can also be summarized as two aspects: One is the invasion of rationality caused by modernization. This is basically similar to the West. Although we have different social systems and values from the West, with the invasion of modernization and the globalization of the market economy, the universal concept has spread across the world, and our values tend to be single. People are blindly pursuing material enjoyment, confused with life, lacking ambition, etc. The other is the decline of traditional Chinese Confucian culture. Since the May Fourth Movement, Confucianism has lost its prestige position in the country for the millennium. For Confucianism, there are universal values that are contrary to modernity, and the values of the old feudal culture should be banned. However, the ethical concepts in Confucianism have influenced Chinese society and shaped Chinese cultural connotations for thousands of years, which makes its rational existence.

The West is a society with traditional Christian faith, and Chinese society has been a cultural system without religious beliefs since ancient times. Western society pays attention to external transcendence. "God" is interpreted as an "absolute" being that is external to human beings and transcends human understanding of worldly knowledge. In this sacred religious belief, people will naturally resort to God's own suffering, good wishes, guilt and stress, etc., expecting God to remedy. All human life expectation and meaning are from God, the sacred thing of this faith. Religion can find its own beliefs through the external sacred transcendence, thus releasing its own confusion, which is the magic of religion. However, when rationality dispels God, people's spiritual roots are lifted. It is a difficult task to return to the realm of faith from the rational state of disintegration.

\section{Confucian culture in Chinese society}

For the Chinese society, Confucian culture pays attention to the inherent transcendence. Mr. Feng Youlan said: "According to the tradition of Chinese philosophy (here referred to as Confucianism), saints should have the character of the inner and outer kings. The mission of Chinese philosophy is to enable people to develop such a character." It can be seen that Confucianism considers it very important to see the inner cultivation, even the core of Confucianism. Here, we can further see that Chinese philosophy pays attention to the internal improvement, that is to say, Confucian culture pays attention not to the external transcendence of deification, but to the inherent transcendence of human beings. Confucius once said: "Whether my claim will be realized or not is left for the destiny to decide." (The Analects of Confucius - Constitution), "The life and death is destiny, and the fortune is at the will of God." (The Analects of Confucius - Yanyuan) Different from the previous Christian faith in God, Confucianism's interpretation of God is that the existence of God and destiny can be understood. Confucius said: "I know the destiny at the age of fifty" (The Analects of Confucius Politics), which shows that in Confucius, the destiny can be recognized and grasped through experience accumulation, so it is not as sacred and unpredictable as God. The uniqueness of Confucianism's interpretation of God and destiny is that they are not the origin of all things, which may further sacred religious colors applied on the ontological and cosmological levels, but make them internalized and subjectivized in the theory of human beings, believing that all of this is in the heart. Mencius said: "One who is kind knows his nature, which means that he knows the destiny. Protecting one' $s$ kindness and preserving his nature to wait for the destiny no matter life is short or long, which is how we live." (Mencius - Heart) Mencius's interpretation of the destiny of this time is also the core interpretation of Confucianism. Compared with the Western religious traditions, Confucianism interprets the concept of transcendence of God and destiny as being within the human body and then becoming the process of human moral practice. This is the most profound expression of Confucian morality. 


\section{Importance of Confucianism to spiritual crisis}

Therefore, Confucianism's salvation of the spiritual crisis is reflected in two aspects: First, the life that makes life meaningful depends on the inner self-consciousness and the self-improvement of morality. The moral world of Confucianism will not be erased by reason; Confucianism will also have its own spiritual crisis, which will fall into the dilemma of value choice because of the lack of moral self-consciousness, full of confusion. However, as long as it does not violate the core values of Confucianism, that is, the individual's temptation to face external material, as long as you choose to enter the correct moral real life, cultivate from within, and reach the inner and outer world, you will gain an "emancipation" of spirit., that is, the "inner saint". Second, personal and social responsibilities do not deviate from each other. Confucian culture emphasizes a kind of social ethical relationship. Although the three norms are already the ruins of the old society, in a sense, these moral concepts are actually a norm of orderly social relations. Among them, the responsibility of the individual and the state or society, the responsibility of the family, etc. will create a special bond. As long as it is not solved, as long as it exists on the balance of the human heart, it will have a great spiritual power to the people.

\section{Conclusion}

The spiritual crisis that human beings generally encounter is mostly the consequences of modernity. Each cultural circle has its own rescue strategy. From the reality of China, Confucianism has been lost for a long time. It has been lost by the modernization and it has lost its market. However, the value of Confucianism is worthy of recognition. If it is given enough attention, it will play a significant role not only in resisting the spiritual crisis, but even in guaranteeing human beings' better survival.

\section{References}

[1] Shatia Drewry: "Alexander Koyev - The Roots of Postmodern Politics", translated by Zhao Qi, Xinxing Publishing House, 2007, p. 4.

[2] Kant: "What is the Enlightenment", "Critique of Historical Rational Criticism", translated by He Zhaowu, The Commercial Press, 1991, p. 22.

[3] Anthony Giddens: Modernity and Self-Identity, Zhao Xudong, Fang Wenyi, Sanlian Bookstore, 1998, p. 16.

[4] Judith M. Bennett: "European Medieval History", translated by Yang Ning and Li Yun, Shanghai Social Sciences Press, 2007, p. 1.

[5] Anthony Giddens: The Consequences of Modernity, Tian He, Yilin Press, 2011, p. 104.

[6] Quoted from: Cui Dahua: "The Modern Destiny of Confucianism", People's Publishing House, 2012 edition, p. 492.

[7] Artur Schopenhauer: "The World as the Will and the Image", Shi Chongbai, Commercial Printing Museum, 1991, p. 10

[8] Quoted from: Shatia Drewry: "Alexander Koyev - The Roots of Postmodern Politics", translated by Zhao Qi, Xinxing Publishing House, 2007, p. 4.

[9] Charles Taylor: The Hidden Worries of Modernity, Cheng Lianyi, Central Compilation Press, 2001, p. 12.

[10] Daniel Bell: "The Cultural Contradictions of Capitalism: Preface to the Reprint of 1978", "Contradictions of Capitalism Culture", translated by Zhao Yifan, Sanlian Bookstore, 1989, p. 21. 